\title{
Review of Toxicity of Allicin from Garlic
}

Kehinde Alare ${ }^{1^{*}}$, Taiwo Alare ${ }^{2}$.

${ }^{1}$ Department of Medicine, Ladoke Akintola University of Technology, Ogbomoso, Oyo State, Nigeria.

${ }^{2}$ Department of Mechanical Engineering, Federal University of Technology, Akure, Ondo State, Nigeria.

*Corresponding Author: Kehinde Alare, Department of Medicine, Ladoke Akintola University of Technology, Ogbomoso, Oyo State, Nigeria

Received date: October 31, 2020; Accepted date: November 27, 2020; Published date: December 10, 2020

Citation: Alare K., Alare T., (2020) Review of Toxicity of Allicin from Garlic, J. Pharmaceutics and Pharmacology Research 3(3); DOI: $10.31579 / 2693-7247 / 021$

Copyright: (C) 2020, Kehinde Alare, This is an open access article distributed under the Creative Commons Attribution License, which permits unrestricted use, distribution, and reproduction in any medium, provided the original work is properly cited.

\section{Abstract}

Allicin components of garlic has been helpful medicinally but adverse effects has been noticed with excessive usage of garlic supplements. The toxicity of the garlic supplements has been carefully reviewed in this article. These toxicities has been linked to its effects and autonomic nervous system and its bactericidal functions. These research also encouraged usage of allicin supplements pills with regulated dosage to garlic concoction taking in most African communities.

Keywords: allicin components; autonomic nervous system; bactericidal functions

\section{Introduction}

Recent studies have shown increase usage of garlic in local herbal medics for different purpose, according to Alare et al. 2020 many side effects were recorded in different patient using garlic herbal concoction [1] in our community.

This article critically review the toxicity involved in the over usage of garlic in order to enlighten the reader on the side effects associated with excessive usage of garlic. This article does not annul the medicinal importance of garlics that has been highlighted in other researches but we it's known that the thin line between drugs and toxins is the dosage.

Some effects of this toxicity may not necessarily be lethal but alters the normal physiological conditions in patients.

\section{Mechanisms of Toxicity}

Mechanism of toxicity of garlic can be traced to its pharmacological active component allicin which is gotten from the metabolism of allicin present in garlic [2]. Allicin being an organosulphur compounds is found to act as a broad spectrum antibiotics [3] having bactericidal effects on both gram-negative and gram-positive bacteria therefore excessive usage can lead to killing of normal body's floral causing colonization of the body by foreign microbes. Although side effects of superinfection due to usage of garlic were not recorded in Alare et al. 2020 [1] but we strongly believe that excessive usage of garlic might lead to infections and even septicemia if proper measures not taking.

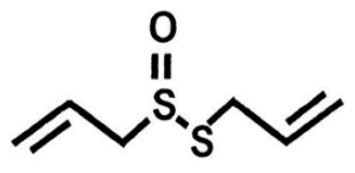

\section{Allicin}

The other and major mechanism of toxicity of allicin is similar to that of organophosphate compounds found in certain plant, this is due of the effect of allicin has on autonomic nervous system due to it's inhibiting activities on cholinesterase thereby making act as an indirect acting muscarinic agonist. When in excess toxicity of cholinergic receptor agonist set in which includes miosis, salivation, sweating, bronchial constriction, vomiting, diarrhea, cognitive disturbances, convulsion and coma [4].

This toxicity is as result of the parasympathetic effects of allicin, diarrhea and hyper-defecation as reported in subjects [1] was as a result of parasympathetic stimulation of the gastrointestinal tract leading to increase GI contractility and movements lead to increase number of toilet visits in patient and this may result in hydration and also hypovolemic shock . Bronchoconstriction may be very lethargic in asthmatic patient using allicin supplements, the effects on the central nervous is due to excess acetylcholine that's not breakdown by cholinesterase.

Some patients experience acute bradycardia and loss of consciousness ${ }^{[1]}$ after excessive intake of garlic concoction over a long period of time, this is due to excessive parasympathetic stimulation on the heart leading to reduced heart rate and reduced force of contraction of the heart thereby reducing the cardiac output. The reduction in cardiac output also lead to reduced blod supply to the brain which could be very lethal as it is evidence as loss of consciousness and syncope.

The toxicity of allicin on the autonomic nervous system can be reverted by parenteral administration of atropine.

\section{Conclusion}

Toxicity of allicin in garlics comes with excessive usage and some side effects are also highlighted so that patient could attribute these changes to usage of garlic concoction and this will greatly help in the proper management of these toxicities because misdiagnosis could be sometimes fatal.

This research also encourages usage of allicin supplement pills rather than garlic concoction because of dosage will be regulated with that to avoid toxicity. 


\section{Acknowledgement}

We acknowledge the following colleagues for their impact the collation of this review, Busayo Adetunji, Tope Odunitan, Samson Afolabi, Oladoja Owonikoko and all our teachers.

\section{References}

1. Alare K, Alare T, Luviano N (2020) Medicinal Importance of Garlic and Onions on Autonomic Nervous System. Clin Pharmacol Biopharm 9: 204-206.

2. Block E, Naganathan S, Putma D, Zhao S (1993) Organosulfur Chemistry of Garlic and Onion: Recent Results. Pure and Applied Chemistry 64: 625-632.

3. Leontiev, R., Hohaus, N., Jacob, C. et al. (2018) A Comparison of the Antibacterial and Antifungal Activities of Thiosulfinate Analogues of Allicin. Sci Rep 8, 6763.

4. Katzung, B.G (2018) Basical \& Clinical Pharmacology. Mc Graw Hill 14 ${ }^{\text {th }}$ Ed.: 121. 